\title{
A APLICAÇÃO DAS CONSTELAÇÕES FAMILIARES DE BERT HELLINGER COMO MÉTODO ẢUXILIAR A CONCILIAÇÃO
}

Taís Ortolan Diel ${ }^{1}$

\begin{abstract}
Resumo: A presente pesquisa surgiu através da experiência desta pesquisadora como Conciliadora do Juizado Especial Criminal de Francisco Beltrão/PR, e também da realização prática de Constelações Familiares, sendo que, busca demonstrar, através deste trabalho, se esta prática é eficaz como método auxiliar à conciliação. Este recurso desafoga o Judiciário, bem como proporciona às partes uma solução mais rápida e branda ao seu litígio. Consoante a isto, as Constelações Familiares de Bert Hellinger estão sendo utilizadas pelos operadores do Direito e têm trazido números impressionantes aos acordos. Este método vai ao fundo do problema e o resolve, proporcionando equilíbrio e harmonia para as partes até então, em conflito. O método de abordagem utilizado no trabalho foi o qualitativo, com realização de pesquisa bibliográfica e documental, assim como, experiências diretas na realização de Constelações Familiares.
\end{abstract}

Palavras-chave: Conciliação. Constelações Familiares de Bert Hellinger. Leis sistêmicas.

\section{THE APPLICATION OF BERT HELLINGER'S FAMILY CONSTELLATIONS AS AUXILIARY METHOD TO THE CONCILIATION}

\begin{abstract}
The present reserch appeared throught the experience of this inquirer as Conciliator of the Criminal Special Court of Francisco Beltrão/PR, and also in the practical realization of Family Constellations, and, throught this work, tries to demonstrate if this practice is efficient as auxiliary method to the conciliation. This method relieves the Judiciary, as well as provide to the parts a quicker and gentle solution to his litigation. Consonant with this, Bert Hellinger's Family Constellations are being used by the operators of the Law and have brought impressive numbers to the agreements. This method goes to the bottom of the problem and resolves it, providing balance and harmony for the parts, which were, in conflict. The method of approach used in the present work was the qualitative, with bibliographical and documentary research, as well as, direct experiences in the realization of Family Constellations.
\end{abstract}

Keywords: Conciliation. Family Constellations of Bert Hellinger. Systemic laws.

\section{Introdução}

Acredita-se que os métodos consensuais de solução de conflitos são a chave para o futuro, pois tratam-se de práticas mais simples, rápidas, eficazes e menos onerosas - se comparados a um processo judicial, tanto para as partes, quanto para o Poder Judiciário. Elas impedem o tumulto de processos, ao passo que, conseguem por fim ao litígio, sem necessitar de todo o desenrolar de uma ação judicial e ao final, de uma sentença.

Com o intuito de estimular as práticas conciliatórias, o Direito Brasileiro tem se flexibilizado e implementado várias normativas que amparam estes métodos. A Resolução no 125/2010 do Conselho Nacional de Justiça (CNJ), foi pioneira neste sentido, tendo por objetivo consolidar os mecanismos consensuais de solução de conflitos, a fim de que sejam amplamente aplicados e disseminados em nosso Judiciário. Deste modo, logo em sua parte introdutória encontramos:

Considerando que, por isso, cabe ao Judiciário estabelecer política pública de tratamento adequado dos problemas jurídicos e dos conflitos de interesses, que

\footnotetext{
1 Pós-graduanda em Direito Processual Civil pelo Centro Universitário UNINTER, Bacharel em Direito pela Universidade Estadual do Oeste do Paraná.
} 
ocorrem em larga e crescente escala na sociedade, de forma a organizar, em âmbito nacional, não somente os serviços prestados nos processos judiciais, como também os que possam sê-lo mediante outros mecanismos de solução de conflitos, em especial dos consensuais, como a mediação e a conciliação (BRASIL, 2010, Resolução nº 125/2010, p. 1).

O enfoque do presente trabalho ficará apenas na conciliação, contudo, para fins didáticos, torna-se oportuna a diferenciação deste método, para o da mediação. Conforme a Lei da Mediação, no 13.140 de 2015, esta é uma técnica em que um terceiro imparcial, escolhido ou aceito pelas partes, ajudando-as e motivando-as a resolverem sua questão através dos meios consensuais, contudo, o mediador não tem poder de decisão, mas ele facilitará o diálogo entre as partes. Por outro lado, a conciliação, segundo o site do CNJ, também possui um terceiro neutro e imparcial, porém é usada em conflitos mais simples, sendo que o conciliador tem um papel mais ativo e, busca uma efetiva harmonização social, sendo utilizada para processos consensuais breves, já a mediação seria um procedimento mais estruturado.

Um método que tem trazido resultados surpreendentes para as conciliações são as Constelações Familiares de Bert Hellinger. Trata-se de uma terapia breve em que as partes podem vivenciar seus problemas de maneira real e totalmente imparcial. O tema será mais aprofundado no decorrer do trabalho, mas as partes conseguem a solução das suas controvérsias de maneira definitiva, ao passo que, este método toca na ferida e a cura, trazendo paz, harmonia e entendimento para aqueles que a vivenciam.

$\mathrm{Na}$ busca por resolver questões pessoais, a pesquisadora descobriu as Constelações Familiares e, através da junção de sua experiência como conciliadora do Juizado Especial Criminal de Francisco Beltrão/PR, o tema do presente trabalho surgiu. A pesquisa ocorreu por meio da vivência direta e indireta nas Constelações, bem como da leitura em bibliografias e reportagens acerca do tema, além da troca de conhecimento com os praticantes da terapia. Assim, o trabalho demonstra que esta terapia tem trazido resultados extremamente positivos e contribuído de forma significativa para a pacificação social tão desejada por nosso ordenamento jurídico e por todos os operadores do Direito.

\section{As Inovações no Ordenamento Jurídico Brasileiro que Estimulam a Prática Conciliatória}

O Conselho Nacional de Justiça (CNJ), em 29 de novembro de 2010, implantou a Resolução $n^{\circ}$ 125/2010 com vistas a regulamentar e incentivar as práticas consensuais, instituindo a Política Judiciária Nacional de tratamento dos conflitos de interesse. Em sua parte introdutória, tem-se que:

[...] a conciliação e a mediação são instrumentos efetivos de pacificação social, solução e prevenção de litígios, e que a sua apropriada disciplina em programas 
já implementados no país tem reduzido a excessiva judicialização dos conflitos de interesses, a quantidade de recursos e de execução de sentenças; [...] ser imprescindível estimular, apoiar e difundir a sistematização e o aprimoramento das práticas já adotadas pelos tribunais; [...] a organização dos serviços de conciliação, mediação e outros métodos consensuais de solução de conflitos deve servir de princípio e base para a criação de Juízos de resolução alternativa de conflitos, verdadeiros órgãos judiciais especializados na matéria (BRASIL, 2010, Resolução nº 125/2010, p. 1).

Data vênia, de acordo com tal Resolução, em seu art. 4", "compete ao Conselho Nacional de Justiça organizar um programa com o objetivo de promover ações de incentivo à autocomposição de litígios e à pacificação social por meio da conciliação e da mediação". Para isso, deverá contar com a cooperação de todos os órgãos do Poder Judiciário, inclusive, firmando parcerias com entidades públicas e privadas, universidades e instituições de ensino, conforme fundamentado no art. $5^{\circ}$.

A Lei no 13.105 de 16 de março de 2015, que instituiu o novo Código de Processo Civil (CPC), incluiu vários artigos na Resolução no 125/2010 do CNJ, através da Emenda no 2, de 08 de março de 2016. Ademais, também editou vários outros para que se adequassem às novas diretrizes lançadas.

A Resolução é categórica ao se criar meios de estimular a conciliação, e assim o faz no art. $7^{\circ}$, que determina a criação dos Núcleos Permanentes de Métodos Consensuais de Solução de Conflitos (Núcleos), por parte dos Tribunais. A coordenação dos Núcleos cabe aos magistrados, e são constituídos por magistrados ativos ou aposentados e servidores, de preferência os que atuam na área.

Similarmente, é disposto no art. $8^{\circ}$, que estabelece a criação dos Centros Judiciários de Solução de Conflitos e Cidadania (Centros ou Cejuscs). Estes são unidades do Poder Judiciário encarregadas da promoção de sessões e audiências de conciliação e mediação, e também da assistência e orientação ao cidadão.

Por conseguinte, na fase pré-processual, as conciliações e mediações deverão ser feitas nos Centros, contudo, na fase processual, elas podem ser realizadas nos Juízos, Juizados ou Varas competentes, é o que traz o $\S^{\circ}$ do art. $8^{\circ}$.

Interessante ressaltar que, a Emenda $\mathrm{n}^{\circ} 2$ criou as Câmaras Privadas de Conciliação e Mediação, disposta nos arts. 12-C à 12-F da Resolução, que têm como objetivo promoverem as sessões de mediação ou conciliação incidentes no processo judicial.

A fim de manter as inovações tecnológicas, o art. 15 cria o Portal da Conciliação, presente no site do Conselho Nacional de Justiça, que tem por intuito divulgar (I) as diretrizes da capacitação dos conciliadores e mediadores, bem como o código de ética, (II) o relatório gerencial do programa, (III) as boas práticas, projetos, ações, artigos e pesquisas, (IV) 
disponibilização de um fórum de discussão, com participação da sociedade, e publicar (V) as notícias relacionadas ao tema e (VI) os relatórios da "Semana da Conciliação".

Outro ponto interessante desta Resolução encontra-se no Anexo III, que dispõe sobre o Código de Ética de Conciliadores e Mediadores Judiciais e, expõe seus princípios e garantias, as regras do procedimento e as responsabilidades e sanções. Deste modo, percebe-se que o Conselho Nacional de Justiça foi eficaz em todas as diretrizes lançadas.

Por fim, vale lembrar que em 2015, o CNJ lançou o Guia de Conciliação e Mediação, a fim de orientar a implantação dos CEJUSCs e dos Núcleos Permanentes, bem como, instituir bases para o desenvolvimento de projetos e iniciativas que visam assegurar os métodos alternativos de solução de conflitos.

O Novo Código de Processo Civil, se inclinou favoravelmente em vários artigos acerca dos métodos consensuais de solução do litígio. Sendo que, logo em seu art. $3^{\circ}, \S 2^{\circ}$ traz que "o Estado promoverá, sempre que possível, a solução consensual dos conflitos” e, no $3^{\circ}$, dispôs que "a conciliação, a mediação e outros métodos de solução consensual de conflitos deverão ser estimulados por juízes, advogados, defensores públicos e membros do Ministério Público, inclusive no curso do processo judicial".

Grande passo fora dado pelo novo CPC através do art. 165, que determina a criação dos CEJUSCs, já anteriormente citados. Esta norma já estava estabelecida pela Resolução ${ }^{\circ}$ 125/2010 do CNJ, contudo, sofreu uma pequena edição pela Emenda n ${ }^{\circ}$ 2. Assim, percebe-se que o novo Código quis positivar também esta diretriz.

Outra inovação trazida pelo novo CPC foi o art. 334, que determina que, em não sendo caso de improcedência liminar do pedido, e a petição inicial tiver preenchido os requisitos essenciais, o juiz designará a audiência de conciliação ou de mediação. Esta deve acontecer com no mínimo, 30 dias de antecedência, sendo que a citação do réu deve ocorrer com pelo menos 20 dias de antecedência.

Os parágrafos que acompanham este artigo também dispõem acerca dos métodos consensuais, tal como o $\S 2^{\circ}$, que diz que poderá ocorrer mais de uma sessão designada para a conciliação e a mediação, desde que não exceda a dois meses da data da primeira realização. Já o $\S 3^{\circ}$, dispõe que esta audiência não será realizada quando ambas as partes manifestarem desinteresse expresso pela composição (I) e quando não seja admitida a autocomposição (II). Do mesmo modo, o autor deverá indicar já na petição inicial seu desinteresse na conciliação, e o réu deverá fazer sua manifestação por petição apresentada com pelo menos dez dias de antecedência da data da audiência, conforme leitura do $\S 5^{\circ}$. 
Uma grande inovação encontra-se no parágrafo $\S 7^{\circ}$, que traz que "a audiência de conciliação ou de mediação pode realizar-se por meio eletrônico, nos termos da lei", ao passo que, anda ao encontro das modernidades que surgem com o passar do tempo. Sendo que, para facilitar esse acesso, foi incluído com a Emenda ${ }^{\circ} 2$ de 8 de março de 2016, o inciso X no art. $6^{\circ}$ da Resolução nº 125/2010 do CNJ, que cria um Sistema de Mediação e Conciliação Digital ou a distância, tanto para a fase pré-processual, quanto para as demandas em curso.

Outro importante ponto para garantir a eficácia da audiência conciliatória está no $\S 8^{\circ}$, determinando que o não comparecimento injustificado do autor ou do réu, será considerado ato atentatório à dignidade da justiça, ocorrendo em multa que será revertida à União ou o Estado, de até $2 \%$ da vantagem econômica pretendida ou do valor da causa.

Nesta celeuma, uma curiosidade se encontra no art. 319, que traz agora como requisito essencial da petição inicial, em seu inciso VII, "a opção do autor pela realização ou não de audiência de conciliação ou de mediação", demonstrando a importância dada à conciliação pelo novo Código.

Assim, existem vários outros artigos tratando da conciliação, contudo, da breve análise destes mais destacados, observa-se que o novo Código de Processo Civil quis deixar bem claro seu interesse para que as partes conciliem e, para que esta seja tentada antes de qualquer coisa, enfatizando isso na necessidade de expressar seu interesse logo na petição inicial, na obrigatoriedade da audiência conciliatória logo no início do litígio e da presença obrigatória das partes, sob pena de multa.

Importante frisar também, acerca da Justiça Restaurativa, que há mais de 10 anos tem sua prática realizada no Brasil, e consiste na utilização de práticas que buscam a solução do conflito de maneira consensual, de modo que, aproxima o infrator e sua vítima, buscando sempre, a pacificação social, sendo que, se trata de um método realizado pelo mediador. Ademais, a Justiça Restaurativa é incentivada pelo CNJ por meio do Protocolo de Cooperação para a difusão da Justiça Restaurativa, firmado em agosto de 2014, pela Associação dos Magistrados Brasileiros (AMB) e diversas outras instituições. Este protocolo visa promover a prática através da mobilização social e da difusão cultural, sempre primando pelos objetivos participativos e humanitários da Justiça Restaurativa e dos preceitos de tolerância e voltados à cultura de paz (BRASIL, 2014, online).

Percebe-se que as legislações têm se empenhado cada vez mais em incentivar a utilização dos métodos consensuais de solução de conflitos. Neste sentido, existe um método que tem auxiliado ainda mais a eficácia das conciliações, ao passo que, impede a reincidência processual 
e contribui para a resolução emocional das partes com relação ao conflito, que são as Constelações Familiares de Bert Hellinger.

\section{As Constelações Familiares de Bert Hellinger}

Anton "Suibert" Hellinger, é um alemão nascido em 18 de dezembro de 1925, exsacerdotista, formou-se em filosofia, teologia e pedagogia. Trabalhou dezesseis anos como membro de uma ordem de missionários católicos na África do Sul, neste período observava os Zulus e o modo como estes resolviam seus conflitos. Após, tornou-se psicanalista e, através da Dinâmica de Grupos, da Terapia Primal, da Análise Transacional e de diversos métodos hipnoterapêuticos, desenvolveu sua própria Terapia Sistêmica Familiar (HELLINGER, 2006b, contracapa).

Outrossim, conforme Oldoni, Lippman e Girardi (2017, p. 124), a infância de Hellinger também foi uma forte influência para seu trabalho, pois, sua maneira de enxergar o mundo, contribuía para que sua família não se rendesse ao nazismo de Hittler, sendo que, suas inúmeras ausências nas reuniões da Organização da Juventude Hitlerista e sua consequente cooperação com uma organização juvenil católica ilegal, o considerou um suspeito de ser inimigo do povo pela Gestapo. Assim, aos 17 anos tornou-se soldado e conheceu a face mais cruel da guerra, acabando como prisioneiro na Bélgica. Após, com 20 anos entrou em uma ordem religiosa católica, trabalhando como missionário na África do Sul, como já exposto acima.

Nesta celeuma, no livro “A fonte não precisa perguntar pelo caminho", Hellinger descreve a construção de seu trabalho para poder chegar até as Constelações Familiares:

Ele começou para mim com a dinâmica de grupo. Aqui pude observar e vivenciar como necessidades e avaliações antagônicas podem ser harmonizadas quando um grupo chega a reconhecer as diferenças, sem a pressão de uma autoridade externa, do puro encontro de uma pessoa com a outra e, partindo desse reconhecimento, pode concordar com uma ação conjunta e, ao mesmo tempo, satisfatória para todos os envolvidos.

A próxima estação nesse caminho foi a psicanálise. Ela constituiu, ao mesmo tempo, um polo oposto à dinâmica de grupo, porque na psicanálise a atenção estava dirigida totalmente aos movimentos opostos do próprio íntimo. Mas aqui também se tratava de realçar o dividido e o reprimido, e aceitar, como equivalente, o lado claro e permitido do consciente.

A terapia primal trouxe-me um aprofundamento das compreensões $\mathrm{e}$ experiências da psicanálise. Neste método tratava-se de expressar sentimentos reprimidos num âmbito protegido, principalmente a tristeza e a dor.

[...] Nessa época entrei em intenso contato com a análise transacional. O que me fascinou, antes de tudo, foi a análise dos scripts [...]. Mais tarde, quando cheguei à compreensão das ordens do amor, pude ver que muitos scripts indicam um emaranhamento, isto é, que o script que uma pessoa segue descreve frequentemente o destino daquele membro da família, com o qual está emaranhado sob a influência da consciência familiar. 
Outras importantes estações foram a hipnoterapia segundo Milton Erickson e a programação neurolinguística (PNL). Junto com a aplicação da observação exata dos mínimos movimentos, elas aplanaram meu caminho para o trabalho com histórias.

Quando então me dediquei à terapia familiar, já estava preparado para ela em muitos aspectos. Com as Constelações Familiares adquiri, uma após outra, compreensões das ordens do amor e os limites e modos de atuação da consciência (HELLINGER, 2007, p. 15 e 16, grifos do autor).

Portanto, nota-se que um extenso caminho foi trilhado pelo terapeuta para chegar até ao seu resultado final, qual seja, a Constelação Familiar. Mas afinal, o que ela é?

Sucintamente, trata-se de uma terapia sistêmica fenomenológica breve, em que o cliente escolhe pessoas para representar os membros da família, como pai, mãe, irmãos, etc., quando esses representantes se colocam no lugar do membro familiar, eles começam a manifestar os sentimentos e pensamentos da pessoa que está representando. É uma vivência surpreendente, pois o representante não perde sua consciência, mas inconscientemente, age igual à pessoa que ele representa, com sintomas físicos, emocionais e psíquicos. Podem ser representados familiares vivos ou mortos que, durante a Constelação, poderão ser a chave do conflito, inclusive trazendo à tona as dinâmicas ocultas que atuam naquele sistema familiar, sendo possível então, a cura tanto almejada (STORCH, 2010, online). O Hellinger Institute coloca a Constelação Familiar como uma ciência, a Hellinger Science ${ }^{\circledR}$, contudo, no presente trabalho, abordaremos ela como um método, e não ciência.

Destarte, esta passagem de Jakob Schneider exprime fielmente acerca das Constelações:

O que há de extraordinário nas Constelações Familiares é primeiramente o método. É singular e fascinante observar, quando um cliente coloca em cena pessoas, sem prévias informações, vivenciam sentimentos e usam palavras semelhantes às deles e, eventualmente, até mesmo reproduzem os seus sintomas (SCHNEIDER, 2007, p. 10).

Ademais, os sentimentos são reais e é inexplicável o que acontece em uma Constelação, visto que, a pesquisadora os presenciou, pois, ao delimitar o tema desta pesquisa, participou como representante em algumas e também fez uma para si, para literalmente poder sentir "na pele" como a dinâmica funciona. Nas palavras de Hunter Beaumont, "não sabemos como é possível aos participantes da Constelação sentirem sintomas que lhe são alheios", e Bert Hellinger recusa-se a especular sobre o assunto: "Não estou capacitado a explicar esse fenômeno, mas ele existe e eu o utilizo" (HELLINGER, 2006a, p. 16).

Portanto, o cliente deve ter a consciência de que será exposto à origem do seu problema, à dor e a tristeza ocasionados por ele, sendo necessária coragem por parte dele, e também dos representantes, pois estes estão entregues aos sentimentos de seus representados, e não fazem a 
mínima ideia de quais eles serão. Contudo, vale ressaltar, este é um serviço de amor, que traz um grande aprendizado para todos que participam (HELLINGER, 2007, p. 177).

Nesta celeuma, cada indivíduo pertence a um sistema familiar, ao passo que, todos possuem um pai e uma mãe, mesmo que não os conheçam, uma vez que, cada ser humano foi gerado a partir de um homem e uma mulher. Assim, carregamos, além da carga genética, também uma carga emocional, pois os traumas ocorridos com nossos antepassados formam emaranhados que ligam os membros do sistema familiar, de modo que, estes traumas ficam armazenados no DNA e são repassados aos demais membros do sistema.

Destarte, o sistema familiar, nas palavras de Bert Hellinger (2006b, p. 98, 99 e 100), "se comporta como se fosse congregado por uma força que liga todos os seus membros e por um sentido de ordem e de equilíbrio que atua em todos da mesma forma”. Além do mais, ele também acredita que os membros do grupo são interligados por laços do destino, onde o destino trágico de um familiar afetará os demais, sendo que, o trabalho desses laços é o de manter a integridade do sistema, contudo, este fardo recai principalmente sobre as crianças, porque elas vêm depois, e a lei da hierarquia também é respeitada.

Se bem observado, esta insinuação é de certa injustiça, pois os membros posteriores e inocentes pagariam pelos antecessores e culpados, entretanto, é isso mesmo que se demonstra, porquanto, "no que diz respeito à compensação, não existe justiça no grupo familiar no que toca à equiparação entre as pessoas" (HELLINGER, 2006b, p. 101).

Essa força que atua sobre o sistema familiar é a de um campo morfogenético, denominado assim por Rupert Sheldrake, que seriam campos de força que determinam certas estruturas, de modo que, os padrões que existem nele, continuam se repetindo. Logo, quem adentra como representante neste campo de força age e sente como o familiar que faz parte dele (HELLINGER, 2007, p. 32, 177 e 182).

Assim, Hellinger constatou que, para que o sistema esteja em harmonia, existem três ordens básicas que devem ser seguidas e, quando estas são violadas, geram um desequilíbrio e formam os nós ou emaranhados. Portanto, essas três ordens são conhecidas como ordens do amor ou leis sistêmicas, e conforme se observa na passagem a seguir:

Sentimos essas três necessidades com a premência de impulsos ou reações instintivas. Elas nos subjugam a forças que nos desafiam, exigem obediência, coagem e controlam; elas limitam as nossas escolhas e nos impingem, queiramos ou não, objetivos que entram em conflito com os nossos desejos e prazeres pessoais (HELLINGER, 2006a, p. 25).

À vista disto, a primeira delas é a do pertencimento, em que cada indivíduo, vivo ou morto, tem o mesmo direito de pertencer ao sistema. Destarte, as crenças que o sistema familiar 
possui, mantém os membros vinculados, não permitindo que ocorram exclusões, pois, o direito de pertencimento é igual perante todos. Quando se exclui um familiar, outro integrante do mesmo sistema irá inconscientemente tomar o seu lugar, tornando por imitar o seu padrão (OLDONI; LIPPMANN; GIRARDI, 2017, p. 37). É o caso da tia que ninguém gosta ou da "sogra chata", entram também nessa lista as pessoas com vícios, com deficiência, o aborto, etc.

Logo, esta lei se refere ao reconhecimento e a vinculação de cada familiar no sistema, cada um tem o seu espaço, e ele é igual para todos. Por isso que, nas dinâmicas, quando há algum membro excluído, faz-se o seu reconhecimento, tratando-o como igual, mostrando que o espaço que lhe é de direito está ali, e que ele também é um membro importante da família.

A segunda lei é a da ordem ou a da hierarquia, uma vez que, aqueles que vieram antes, tem prioridade sobre os que vieram depois (HELLINGER, 2007, p. 47). Assim, quando um filho se sente superior aos pais ou se mete nos assuntos destes, ou os irmãos mais novos sobre os mais velhos, esta ordem é rompida. Por consequência, cada membro deve ocupar o seu lugar, visto que, o não reconhecimento disso acarretará a desordem da sua vida e das dos demais.

Por fim, a terceira ordem é a do equilíbrio entre o dar e o receber, da compensação nas nossas relações. Quem dá algo, espera algo em troca, tem-se a ideia da igualdade entre dar e receber, e ocorrem violações também quando algum familiar recebe mais herança do que outro, por exemplo (OLDONI; LIPPMANN; GIRARDI, 2017, p. 39 e 40). Outrossim, ela também pode ser entendida como um reflexo da primeira ordem, ao passo que, quando se nega a um familiar o seu direito de pertencimento, a consciência da família busca restabelecer essa ordem violada, compensando com outro familiar, geralmente um nascido posteriormente, criando então, uma ligação entre o excluído e o compensado (HELLINGER, 2007, p. 46).

Ademais, estamos limitados a estas leis, se as seguimos em plena harmonia, elas tornam nossos relacionamentos possíveis, contudo, se as rompemos, é aí que surgem os problemas. O rompimento de qualquer uma dessas leis provoca um desequilíbrio e têm-se os chamados traumas, que formarão nós ou emaranhados, que então ligarão os familiares a este acontecimento. Por conseguinte, os emaranhados são identificados através de acontecimentos não resolvidos do passado, que irão refletir em condutas impulsivas e sentimentos excessivos. Por isso que o facilitador deve estar atento às demonstrações de emoções exacerbadas e às condutas que fogem da normalidade, porque provavelmente haverá uma situação a ser resolvida aí (HELLINGER, 2006a, p. 25 e 163).

Feitas tais considerações, a aplicação das Constelações Familiares tem ganhado força no âmbito do Direito, ao passo que, surge um novo ramo deste, o Direito Sistêmico. Assim, este método terapêutico vem para humanizar o campo jurídico e seus operadores, a fim de curar as 
feridas causadas pelos relacionamentos que acabam se desdobrando em inúmeros processos. É um olhar pela ótica da emoção, e não apenas da razão.

\section{O Direito Sistêmico Brasileiro}

Pioneiro nesta prática no Direito Brasileiro, o Juiz Sami Storch, atualmente lotado na Comarca de Itabuna, na Bahia, dedica-se a este assunto desde 2004, e estabelece que esta definição "surgiu da análise do Direito sob uma ótica baseada nas ordens superiores que regem as relações humanas, segundo a ciência das Constelações Sistêmicas"2. Este juiz brasileiro é internacionalmente conhecido pela difusão do Direito Sistêmico, sendo inclusive convidado pelo próprio Bert Hellinger para palestrar sobre esta nova prática em um Congresso Internacional na Alemanha em abril de 2015.

Destarte, esta nova ramificação visa à solução do conflito, não apenas observando a disputa das partes, mas sim, através da cooperação, ao ponto que vai ao encontro da pacificação social almejada em diversos dispositivos de nossa legislação, deixando de lado a ótica do desacordo e do conflito que, infelizmente, é a que mais se perfaz em nosso Direito (OLDONI; LIPPMANN; GIRARD, 2017, p. 42).

Interessante é a definição dada por Amilton Plácido da Rosa, Procurador de Justiça aposentado do Mato Grosso do Sul, em entrevista dada ao Jornal Carta Forense:

O Direito Sistêmico, em termos técnico-científico, é um método sistêmicofenomenológico de solução de conflitos, com viés terapêutico, que tem por escopo conciliar, profunda e definitivamente, as partes, em nível anímico, mediante o conhecimento e a compreensão das causas ocultas geradoras das desavenças, resultando daí paz e equilíbrio para os sistemas envolvidos (ROSA, 2016, online).

Data vênia, percebe-se que o Direito Sistêmico vem para dar uma visão mais humanista a um processo judicial, bem como, aos operadores do Direito, de modo que, muitas vezes, mesmo após uma sentença, tem-se a sensação de que o conflito não está findo, pois, ainda há muita mágoa contida e escondida por detrás desse processo. Por isso que, as Constelações Familiares são brilhantes nesse ponto, visto que, irão até o cerne do problema, para que este seja, por fim, solucionado.

Ademais, a pesquisadora viu isto ocorrer na prática, pois atuou como Conciliadora no Juizado Especial Criminal da Comarca de Francisco Beltrão/PR de 2016 à 2018, sendo corriqueiro, por exemplo, que um casal que se separou tenha processos na Vara de Família, de guarda e alimentos, tenha também processos na Vara Criminal, por Lei Maria da Penha, não

\footnotetext{
${ }^{2}$ Informações constantes na página inicial do site https://direitosistemico.wordpress.com/ do Juiz Sami Storch.
} 
bastasse, acabam possuindo, também, no Juizado Especial Criminal por ameaça, lesão corporal, injúria, difamação, etc. Isto é muito mais comum do que se imagina, e é alarmante, visto que, as partes não conseguem mais ter diálogo até para as coisas mais simples. Sem contar que, se elas têm novos relacionamentos, o(a) ex-companheiro(a), geralmente tem processos contra o(a) atual, e vice-versa, o que acaba por se tornar uma bola de neve, a qual nem uma sentença judicial consegue resolver.

Outrossim, isso ocorre também entre brigas de vizinhos, desentendimentos entre familiares, e que cada vez mais vão envolvendo outros membros dos seus sistemas. Chega a ser frustrante, porque as partes até conciliam em audiência, mas lá fora não conseguem pôr em prática, e muitas vezes, passa algum tempo e estão novamente com os nomes na pauta do dia.

Contudo, é claro que existem casos em que as conciliações ocorrem e são eficazes, em que os envolvidos conseguem reestabelecer a harmonia, ou mesmo se ignorarem e cada um seguir com a sua vida, contudo, quando isto não ocorre, o Direito torna-se um tanto quanto limitado, visto que, não consegue chegar à essência do desentendimento, que se toca através dos sentimentos.

Ademais, a Resolução n ${ }^{\circ}$ 125/2010 do CNJ, abre os caminhos para diferentes formas de se conciliar em um processo, podendo então, o Direito Sistêmico adentrar nessas esferas judiciais como um método eficaz e respeitado, devendo ser utilizado por conciliadores, mediadores, advogados, promotores e magistrados, ao passo que, coloca em equilíbrio a vida de seus clientes ou partes através das leis sistêmicas de Bert Hellinger (OLDONI; LIPPMANN; GIRARDI, 2017, p. 45).

Assim, aprender a dinâmica que envolve as ordens do amor, é de grande valia para os operadores do Direito, uma vez que, aprofundar-se nesse assunto trará mais conhecimento acerca das dinâmicas ocultas que rondam as desavenças e conflitos, pois, a motivação das partes muitas vezes pode estar ligada às causas que advêm de seus antepassados, podendo ser pequena a parcela que diz respeito à outra parte que se encontra em litígio (STORCH, 2017, online).

Nesta celeuma, esta prática pode ser aplicada em todos os ramos do Direito, já que, em todos os nossos relacionamentos há atuação de influências da família de origem, sendo assim, os nós serão desfeitos e o equilíbrio será restabelecido, ao passo que, a parte será libertada das condutas que a ligavam àquela circunstância. Logo, questões relacionadas à violência, dificuldade de se relacionar, diversos tipos de bloqueios, inseguranças, vícios, problemas no trabalho, podem ser potencialmente resolvidos através deste método (STORCH, 2017, online).

Ademais, as Constelações têm tido maior aplicabilidade no Direito de Família, tendo em vista, o enorme caráter afetivo que envolve este tipo de conflito, de modo que, justamente por 
este motivo, a animosidade entre as partes é mais acentuada (DIAS, 2015, p. 49 apud OLDONI; LIPPMANN; GIRARDI, 2017, p. 68). Seguindo este raciocínio, é de se esperar que as Constelações tenham um grau elevado de acordos, pois, seus conflitos que, tem bases totalmente emocionais, serão resolvidos, evitando situações como as de alienação parental, que são comuns nestes casos.

Neste diapasão, o Juiz Sami Storch realizou entre outubro de 2012 e setembro de 2013, seis palestras vivenciais na Comarca de Castro Alves/BA, com o tema "Separação de casais, filhos e o vínculo que nunca se desfaz", com partes de ações judiciais na área de família, totalizando entre 40 a 100 participantes em cada evento. Inicialmente, o magistrado palestra sobre os vínculos sistêmicos familiares, sobre os motivos que levam às crises e como enfrentálas, de modo a não envolver os filhos no conflito, visto que, estes sempre são os mais prejudicados. Após este faz uma meditação, em que os presentes buscam o real sentimento do amor. Por fim, tem contato direto com as Constelações, uma vez que, as partes podem constelar a sua própria questão, podem participar como representante da Constelação de outra pessoa ou simplesmente estarem como observadores (STORCH, 2016, online).

Os resultados obtidos com estas vivências foram surpreendentes, ao passo que, das 90 audiências dos litígios nos quais, pelo menos uma das partes participou das palestras, foram obtidas $91 \%$ de conciliações, nos demais foi de $73 \%$. Contudo, quando ambas das partes participaram das vivências, este índice chegou a 100\%! (BANDEIRA, 2014, online). É um resultado impressionante e encorajador, e os números demonstram que os frutos colhidos são os melhores possíveis, nas palavras do próprio Juiz:

Posteriormente, quando da realização das audiências de conciliação, os acordos acontecem de forma rápida e até emocionante, pois os que participaram das vivências tendem a desarmar seus corações e reconhecer que, por trás das acusações e dos rancores mútuos, existe um sentimento de amor verdadeiro e a dor da frustração (STORCH, 2016, online).

Esta prática tende, tão somente em reduzir os processos judicias, como também trazer qualidade de vida a uma família até então estava fragmentada e ferida, de modo que, auxilia seus membros a solucionarem suas divergências e a criarem um ambiente harmônico e de paz, onde seus filhos poderão crescer mais saudavelmente (STORCH, 2016, online).

Segundo dados do CNJ, pelo menos 16 Estados e o Distrito Federal já aplicam esta técnica em seus processos, inclusive, ocorrendo premiações. Em Goiás, o Projeto Mediação Familiar, do $3^{\circ}$ CEJUSC da Comarca de Goiânia, rendeu ao Tribunal de Justiça de Goiás o $1^{\circ}$ lugar no V Prêmio Conciliar é Legal, promovido pelo CNJ, além de receber em 2014 uma 
menção honrosa no XI Prêmio Innovare, concedido pelo Instituto Innovare (FARINELLO, 2018, online).

O Estado de Santa Catarina também se tem mostrado pioneiro na prática das Constelações, sendo utilizada em Florianópolis pela Juíza Vânia Pertemann, junto ao Fórum da própria UFSC, com o projeto "Conversas de Família", que auxilia as partes no processo de divórcio, tratando-se de uma sessão coletiva feita antes das audiências, onde as partes são convidadas a participar e, quem quiser, poderá constelar (DUARTE, Clic RBS, 2017, online). Conforme informações do Tribunal de Justiça de Santa Catarina, os encontros acontecem quinzenalmente com uma média de 24 participantes por vez. Assim, segundo as palavras da própria Juíza:

O projeto envolve uma visão transdisciplinar não só por abrir portas para várias técnicas, mas também por humanizar todos os envolvidos, desde a magistrada até as partes, com um grande entendimento sobre todos os aspectos da vida que interferem inconscientemente na tomada de decisões (SANTA CATARINA, TJSC, 2017, online).

Vale destacar também, que foi implantada pela UFSC a matéria de "Direito Sistêmico" na Graduação e no Mestrado Profissional em Direito pela professora Grazielly Alessandra Baggenstoss, para os clientes do Núcleo de Práticas Jurídicas (NPJ), na área de Direito das Famílias, tornando-se assim, a primeira instituição de ensino brasileira a estudar cientificamente o método e a aplicar, na modalidade de extensão, as técnicas para pacificação de conflitos familiares (SANTA CATARINA, UFSC, 2017, online).

Noutro giro, Amilton Plácido da Rosa, em entrevista já citada anteriormente à Carta Forense em 2016, demonstra que também podem ser realizadas Constelações sociais ou coletivas, em que serão discutidos assuntos de interesse geral, como Meio Ambiente, Patrimônio Público, Cidadania, entre outros, contribuindo enormemente para o desempenho do Ministério Público como guardião dos interesses sociais. Inclusive, este Promotor já constelou sobre a nascente do Córrego Azul, de Bodoquena/MS, que era ameaçada pela ação de turistas, a Construção da Usina de Belo Monte e a PEC 37. Acerca desta última, faz-se interessante sua reprodução aqui, a fim de trazer entendimento de como seria uma Constelação envolvendo esse tipo de conflito.

Em relação à PEC 37. Diante da ameaça da aprovação da PEC 37, que pretendia deixar todas as investigações criminais na mão da Polícia, em detrimento de outras instituições, como o Ministério Público, resolvi ver o que estava por trás da tal pretensão. O que se revelou é que o Poder Executivo Federal queria mudar uma situação, manipulando o Legislativo Federal. Na Constelação, ele apareceu, inicialmente, bem atrás daquele Poder e, perguntado o que ele ali fazia, respondeu: daqui eu manipulo tudo. A polícia, por sua vez, apareceu, de 
pronto, alinhada com a sociedade e com o Ministério Público, o que fazia com que o Executivo se escondesse atrás do Legislativo. Quando a Polícia saiu desse alinhamento para ir buscar respaldo e apoio no Executivo, este Poder sentiu força e saiu detrás do Legislativo. A Polícia alegava que ela se sentia desprestigiada e buscava força e reconhecimento no Executivo. Mesmo alertada pelo MP que aquela não seria a postura ideal para ela conseguir o que ela queria, ela não desistiu de procurar no Executivo Federal o que ela só alcançaria com o apoio da sociedade. Houve outros movimentos, mais o essencial veio à luz e o resultado concreto foi aquele que todos sabemos, a PEC foi totalmente derrotada pela força e mobilização da sociedade (ROSA, 2016, online).

Ademais, a prática também vem sendo difundida no âmbito penal, englobando processos das Varas Criminais e de Execução Penal. Contudo, há de se frisar que a natureza de um processo penal é diferente do civil, pois, neste último a vítima não é parte no processo, quem exerce a figura de autor da ação é o Ministério Público, assim, a vítima é substituída pelo Estado, o que não ocorre no processo civil, em que a vítima será efetivamente a autora da ação, por este motivo que as leis sistêmicas serão aplicadas diferentes em cada âmbito (OLDONI; LIPPMANN; GIRARDI, 2017, p. 109).

Faz-se mister traçar aqui, a relação entre a estrutura da justiça penal e as leis sistêmicas de Bert Hellinger, brilhantemente feita por Oldoni, Lippman e Girdari (2017, p. 110 e 111), no seu recente livro intitulado "Direito Sistêmico", a fim de entender como caberia a aplicação das ordens do amor neste contexto. Portanto, como já explanado anteriormente, as três leis sistêmicas são a da hierarquia, do pertencimento e do equilíbrio, logo, na primeira, remete-se ao passado e verifica-se que antigamente a solução dos conflitos cabia aos particulares, e somente posteriormente que surgiu a figura de um Procurador para representar os direitos lesados de uma vítima, que poderia ser o rei, o soberano ou um senhor. Então, primeiro aparece a sociedade e, após o Estado, sendo que, no modelo atual utilizado, essa hierarquia estaria sendo violada.

Já pela segunda lei, a do pertencimento, também se verifica uma violação, ao passo que, a vítima não pertence ao conjunto que decidirá acerca da punição ou não de seu agressor, contudo, ela precisa ser chamada ao processo para que possa escolher pela não punição ou redução da sanção ao seu infrator. Do mesmo modo, o autor do fato deve pertencer ao sistema, isto porque, ele acaba ficando à mercê da sentença, sendo um tanto quanto excluído de todo o trâmite processual, devendo ocorrer também, a aproximação entre as partes envolvidas, visto que, pela violência foram separados (OLDONI; LIPPMANN; GIRARDI, 2017, p. 114, 116, 117).

Ademais, vale a ressalva de que, nas infrações do âmbito do Juizado Especial Criminal há esta aproximação entre a vítima e seu agressor, inclusive, ela pode optar pelo não prosseguimento do feito, fazendo-se assim uma conciliação, até para os crimes de ação pública incondicionada, pois neste caso, quando há vítima determinada, aplica-se o Enunciado $\mathrm{n}^{\circ} 99$ do FONAJE, dispondo que "nas infrações penais em que haja vítima determinada, em caso de 
desinteresse desta ou de composição civil, deixa de existir justa causa para ação penal" (BRASIL, FONAJE, CNJ, online).

Por fim, a última ordem é a do equilíbrio, e talvez seja a mais relevante para discussão, ao passo que, esta harmonia deveria ser encontrada pelas próprias partes envolvidas no litígio, e não por um terceiro, pois a imposição de uma pena não desfará o nó criado pelo fato criminoso e, mesmo que eles não tenham relacionamento algum, deve haver a compensação, as partes em conflito devem se sentir quites umas com as outras. Outrossim, quando não existe uma vítima estabelecida, para que ocorra o equilíbrio, é necessário que o infrator tenha consciência de que a pena imposta a ele é adequada ao fato delituoso praticado. Logo, esta lei sistêmica também é violada, e conclui-se que o sistema penal, do modo como ele está estruturado, não encontra harmonia entre as três ordens, o que reflete no campo morfogenético do sistema a ele subordinado (OLDONI; LIPPMANN; GIRARDI, 2017, p. 118, 119 e 122).

Assim, com as Constelações, a vítima e seu agressor resolveriam as suas questões e se libertariam dos sentimentos ruins que os prendem, sendo fundamental, tanto para a vítima poder superar os fatos ocorridos quanto para o agressor aceitar a sua punição, sem rancores ou sentimentos vingativos. Nesta celeuma, é interessante esta colocação de Bert Hellinger.

O ódio nos prende ao agressor. A vítima está livre do agressor quando se retira. Assim, deixa o agressor com a sua própria alma e seu próprio destino. Isso é uma forma de respeito. Dessa forma, a vítima fica livre. Esse afastamento do agressor e daquilo que fez para o centro vazio - assim denomino isso - dá força e, de vítima, nos transformamos em protagonistas (HELLINGER, 2007, p. 42).

Diante do exposto e, tendo em vista que, o Direito Penal, excetuando-se aqui o ramo dos Juizados Especiais, não admite que acordos sejam feitos no curso do processo criminal, torna-se um tanto quanto inviável a aplicação das Constelações Familiares como método a substituir a pena, mas é notório, que Juízes têm levado em conta a participação do réu nas Constelações como atenuante do artigo 66 do Código Penal, pois, em regra, ela está sendo utilizada nos casos de violência doméstica e tráfico de drogas (OLDONI; LIPPMANN; GIRARDI, 2017, p. 118, 119 e 122).

Semelhantemente, está sendo aplicado pelo CEJUSC em Francisco Beltrão/PR com o projeto "Desatando Nós", onde as Constelações Familiares estão sendo feitas com as vítimas de violência doméstica. Assim, ocorre uma triagem pelo juízo da Vara Criminal, na qual, ao receber a medida protetiva ou o inquérito policial, intima-se a vítima e a convida a participar do projeto. Após, ocorre uma palestra instrutória, que se explana acerca das Constelações Familiares, bem como sobre as leis sistêmicas. Por conseguinte, as mulheres são convidadas a participarem de oficinas que englobam diálogos e exercícios sistêmicos, com a realização da Constelação 
propriamente dita. Outrossim, o projeto é recente e teve início em abril de 2017, sendo que, foram atendidos aproximadamente 250 (duzentos e cinquenta) beneficiários no ano passado, e os resultados foram tão positivos, que também os agressores estão comparecendo aos encontros, a convite das vítimas. Ademais, muito em breve a técnica será desenvolvida em outras Varas da Comarca $^{3}$.

Semelhante aplicação tem ocorrido na Comarca de Paróbe/RS, onde a Juíza Lizandra dos Passos criou o projeto "Justiça Sistêmica: Resolução de conflitos à luz das Constelações Familiares", o qual foi implementado inicialmente na área de violência doméstica, tendo em vista a ampla demanda. Foram iniciados dois grupos, um destinado aos homens, que recebiam como medida cautelar (além da medida protetiva), e no outro as mulheres eram convidadas a participar. Com o passar do tempo, percebeu-se a necessidade de fazer um grupo misto - sem colocar vítimas e agressores no mesmo -, para que houvesse a reconciliação do feminino com o masculino. Assim, neste tipo de processo, não é feito o acordo, contudo, nota-se que é criado um empoderamento feminino e, num período pesquisado de seis meses, o índice de não reincidência processual foi de 93,8\%. Entretanto, há ainda o grupo de Direito de Família e Sucessões, que auxilia nos processos de guarda, alimentos, inventário e partilha, e o grupo que atua com os menores acolhidos na Casa da Criança (SALGADO, 2018, online).

Noutro giro, segundo Oldoni, Lippmann e Girardi (2017, p. 131), no campo da Execução Penal, existem dispositivos que permitem de certo modo a aplicação das Constelações Familiares, que são aqueles contidos na Lei de Execução Penal, $n^{\circ}$ 7.210/84, que tratam da assistência social ao apenado. Assim, a terapia entra como método para auxiliá-lo na aceitação e cumprimento de sua pena, bem como evitar a reincidência, de modo que, o mesmo pagará pelo crime que fez e se libertará do emaranhado formado por ele. Interessante ponto de vista é o explanado pelos autores:

A importância de ouvir o sujeito que cumpre uma pena privativa de liberdade é enorme. Ele foi excluído do seu sistema familiar e social, não mais pertencendo a eles, sendo colocado a força num ambiente de encarceramento coletivo. $\mathrm{Na}$ família e no grupo foi proibido de ficar e no sistema prisional forçado a estar. Evidente que não consegue pertencer a lugar algum (OLDONI, LIPPMANN E GIRARDI, 2017, p. 132 e 133).

É necessário olhar para as causas do crime, para as razões que levam o sujeito a cometer um tipo penal, sendo que, a figura da família tem enorme interferência na construção do indivíduo, é através dela que se têm as primeiras noções de valores, como respeito e honestidade,

\footnotetext{
${ }^{3}$ Informações cedidas oralmente por Kátia Klipel, uma das facilitadoras que auxilia este programa e também é Servidora do Tribunal de Justiça do Estado do Paraná.
} 
sendo que, na grande maioria das vezes, as raízes do problema também se encontram nela. Por isso, há a necessidade de aplicar as Constelações aos apenados, de modo que, terão uma contribuição significativa para a diminuição da reincidência criminal, pois, conforme Oldoni, Lippmann e Girardi (2017, p. 134), "pode-se afirmar que a reincidência é a repetição do comportamento pela manutenção oculta do problema".

Nada obstante, advogados também estão aplicando a técnica com seus clientes, ao passo que, a advocacia sistêmica possui um caráter pacificador, visando humanizá-la, pois analisa o conflito de forma otimista e transformadora, voltando o olhar com empatia para as partes, com uma abordagem não contenciosa e sempre visando a melhor solução para o conflito que estão enfrentando (OLDONI; LIPPMANN; GIRARDI, 2017, p. 47 e 48).

Neste contexto que foi criada em abril de 2017 a primeira Comissão de Direito Sistêmico do Brasil, pela Ordem dos Advogados da Seccional de Santa Catarina, idealizada pela advogada Eunice Schlieck, também Presidente da Comissão, na qual auxilia os escritórios que queiram desenvolver a prática da advocacia sistêmica, e realiza encontros multidisciplinares acerca do tema. Do mesmo modo, a Subseção de Balneário Camboriú e de Itajaí, também criaram uma Comissão de Direito Sistêmico, sendo que, outras Subseções também já demonstraram impulsos para a criação de outras comissões, bem como na disseminação do direito sistêmico (OLDONI; LIPPMANN; GIRARDI, 2017, p. 50 e 51).

No Paraná, a Comarca de São José dos Pinhais foi a primeira a fundar uma Comissão de Direito Sistêmico, demonstrando seu pioneirismo acerca da temática, abrindo campo para outras Comarcas seguirem seus passos, sendo que, a OAB Paraná, se pronunciou recentemente acerca do tema, inaugurando, a partir do mês de julho de 2018, a Comissão de Direito Sistêmico do Paraná (PARANÁ, OAB Paraná e OAB São José dos Pinhais, 2018, online).

\section{Considerações Finais}

Verifica-se que o Direito Brasileiro cada vez mais tem estimulado as práticas não conflitivas, pois, com o passar dos anos, percebeu-se que o futuro não pode estar baseado no litígio, mas sim, no acordo. Desta forma, os métodos consensuais de resolução de conflitos são ferramentas extremamente benéficas, que devem ser aprimoradas e difundidas cada vez mais em todos os segmentos da sociedade.

Assim, as Constelações Familiares de Bert Hellinger e, consequentemente, o Direito Sistêmico, ainda são assuntos novos em nosso sistema jurídico, contudo, os operados do Direito têm percebido a sua importância e valor, buscando conhecer esta técnica e aplicá-la, de modo que, já são 16 (dezesseis) Estados que a utilizam, devendo ser propagada e aperfeiçoada cada vez 
mais, pois sua utilização têm demonstrado ótimos resultados, trazendo às conciliações índices que beiram os $100 \%$ de êxito.

O amplo campo temático da Constelação permite que ela seja aplicada a todo o tipo de conflito e situação, entretanto, na esfera judicial, ela esbarra apenas em alguns tipos de procedimentos, como é o caso do Processo Penal. Porém, isto não impede que ela seja aplicada na Vara Criminal nos casos de violência doméstica e tráfico de drogas, como circunstância atenuante, sendo também aplicada ao apenado no âmbito da Execução Penal.

Na esfera Familiar, Cível e de Sucessões, bem como nos Juizados Especiais Cíveis e, dependendo do crime, no Juizado Especial Criminal, a aplicação deste método se torna muito mais fácil, pois, autor e réu possuem maior contato e podem celebrar acordos, são as partes que darão o rumo do processo, diferentemente do que ocorre da esfera Criminal, em que o Ministério Público é o detentor do direito de ação.

Data vênia, as Constelações Familiares buscarão a raiz do conflito, que, na maioria das vezes, esta não é tratada durante o processo, visto que, ele geralmente envolve aumento de disputa e controvérsia, do que consenso e entendimento. Assim, a ferida será encontrada e curada, trazendo às partes, um novo olhar sobre o litígio, um olhar de paz e resolução, deixando o campo aberto para que aconteça a conciliação, bem como, ocorra a melhoria da qualidade de vida das partes conflitantes.

Diante do exposto, é notório que uma sentença judicial nem sempre põe fim ao conflito, pois ela não trata da parte emocional que ele engloba, ao passo que, a aplicação das Constelações Familiares humaniza o processo judicial, trazendo harmonia, não somente para as partes em disputa, mas para todos aqueles que dela participam, além de que, seu índice altíssimo de conciliações, mostra que ela é uma ferramenta valiosa para o Judiciário alcançar a pacificação social e evitar a reincidência processual.

\section{Referências Bibliográficas}

ASSOCIAÇÃO BRASILEIRA DE NORMAS TÉCNICAS. NBR 6023: Informação e documentação - referências - elaboração. Rio de Janeiro, 2002.

ASSOCIAÇÃO BRASILEIRA DE NORMAS TÉCNICAS. NBR 10520: Informação e documentação - citações em documentos - apresentação. Rio de Janeiro, 2002.

BANDEIRA, Regina. Juiz consegue $100 \%$ de acordos usando técnica alemã antes das sessões de conciliação, 17 de novembro de 2014. Portal CNJ. Notícia. Disponível em: <http://www.cnj.jus.br/noticias/cnj/62242-juiz-consegue-100-de-acordos-usando-tecnica-alemaantes-das-sessoes-de-conciliacao>. Acesso em: 12 set. 2017.

BRASIL. Associação dos Magistrados Brasileiros. Protocolo de Cooperação Interinstitucional para Difusão da Justiça Restaurativa, 14 de agosto de 2014. Brasília, DF. Disponível em: <http://www.amb.com.br/jr/docs/protocolo.pdf>. Acesso em 12 set. 2017. 
CNJ. Conciliação e Mediação. Portal da Conciliação. Disponível em: <http://www.cnj.jus.br/programas-e-acoes/conciliacao-e-mediacao-portal-da-conciliacao>. Acesso em: 11 set. 2017.

Enunciados Criminais do FONAJE. Disponível <http://www.cnj.jus.br/corregedoriacnj/redescobrindo-os-juizados-especiais/enunciadosfonaje/enunciados-criminais>. Acesso em: 17 set. 2017.

Guia de Conciliação e Mediação, 16 de maio de 2015. Disponível em: <http://www.cnj.jus.br/files/conteudo/destaques/arquivo/2015/06/1818cc2847ca50273fd110eafd b8ed05.pdf $>$. Acesso em: 15 set. 2017.

Resolução no 125/2010, de 29 de novembro de 2010. Disponível em: $<$ http://www.cnj.jus.br/images/atos_normativos/resolucao/resolucao_125_29112010_110320161 62839.pdf>. Acesso em: 11 set. 2017.

Lei no 13.105, de 16 de março de 2015, Código de Processo Civil. Diário Oficial da República Federativa do Brasil, Brasília, DF. Disponível em: <http://www.planalto.gov.br/ccivil_03/_ato2015-2018/2015/lei/113105.htm>. Acesso em 11 set. 2017.

. Lei n ${ }^{\circ}$ 13.140, de 26 de junho de 2015, Lei da Mediação. Diário Oficial da República Federativa do Brasil, Brasília, DF. Disponível em: <http://www.planalto.gov.br/ccivil_03/_ato2015-2018/2015/Lei/L13140.htm>. Acesso em 11 set. 2017.

DUARTE, Gabriele. Juízes catarinenses usam técnica da constelação familiar sistêmica para resolver conflitos, 9 de setembro de 2017. Clic RBS. Notícia. Disponível em: <http://dc.clicrbs.com.br/sc/estilo-de-vida/noticia/2017/09/juizes-catarinenses-usam-tecnica-daconstelacao-familiar-sistemica-para-resolver-conflitos-9891698.html>. Acesso em: 16 set. 2017.

FARINELlO, Luiza. Constelação Familiar: no firmamento da Justiça em 16 Estados e no DF, 04 de abril de 2018. Portal CNJ. Notícia. Disponível em: <http://www.cnj.jus.br/noticias/cnj/86434-constelacao-familiar-no-firmamento-da-justica-em16-estados-e-no-df >. Acesso em 02 jul. 2018.

HELLINGER, Bert. A fonte não precisa perguntar pelo caminho. 2. ed. Patos de Minas, MG: Atman, 2007.

. A simetria oculta do amor: porque o amor faz os relacionamentos darem certo. 6 . ed. São Paulo: Cultrix, 2006a.

$2006 b$.

. No centro sentimos leveza: conferências e histórias. 2. ed. São Paulo: Cultrix,

OLDONI, Fabiano; LIPPMANN, Márcia Sarubbi; GIRARDI, Maria Fernanda Gugelmin. Direito Sistêmico: Aplicação das leis sistêmicas de Bert Hellinger ao Direito de Família e ao Direito Penal. 1. ed. Joinville, SC: Manuscritos, 2017.

PARANÁ. Portal de Notícias da OAB Paraná. OAB Paraná terá Comissão de Direito Sistêmico, 03 de julho de 2018. Notícia. Disponível em: <https://www.oabpr.org.br/oab-criaracomissao-de-direito-sistemico/>. Acesso em: 17 jul. 2018.

PARANÁ. Portal de Notícias da OAB São José dos Pinhais. Comissão de Direito Sistêmico impressiona autoridades com nova proposta para o Judiciário, 02 de julho de 2018. Notícia. Disponível em: <https://oabsjp.org.br/comissao-de-direito-sistemico-impressiona-autoridadescom-nova-proposta-para-o-judiciario/>. Acesso em 17 jul. 2018. 
ROSA, Amilton de Plácido da. Direito Sistêmico e Constelação Familiar, 2 de setembro de 2016. Entrevista. Disponível em: <http://www.cartaforense.com.br/conteudo/entrevistas/direitosistemico-e-constelacao-familiar/16914>. Acesso em: 14 set. 2017.

SALGADO, Mário. Parobé utiliza constelações para solucionar conflitos, 26 de março de 2018. Jornal do Comércio. Entrevista. Disponível em: <https://www.jornaldocomercio.com/_conteudo/2018/03/cadernos/jornal_da_lei/617551-parobeutiliza-constelacoes-para-solucionar-conflitos.html>. Acesso em: 09 jul. 2018.

SANTA CATARINA. Portal de Notícias da UFSC. UFSC é pioneira em aplicar técnicas para pacificação de conflitos familiares na graduação e mestrado, 2 de junho de 2017. Notícia. Disponível em: <http://noticias.ufsc.br/2017/06/ufsc-e-pioneira-em-aplicar-tecnicas-parapacificacao-de-conflitos-familiares-na-graduacao-e-mestrado/>. Acesso em: 02 jul. 2018.

SANTA CATARINA. Tribunal de Justiça. Sala de Imprensa. Multidisciplinariedade faz projeto Conversa de Família ter baixa recidiva em ações, 7 de setembro de 2017. Notícia. Disponível em: <https://portal.tjsc.jus.br/web/sala-de-imprensa/-/multidisciplinaridade-fazprojeto-\%60conversa-de-familia\% $2 \% \mathrm{BF}$-ter-baixa-recidiva-em-

acoes?redirect=https\%3A\%2F\%2Fportal.tjsc.jus.br\%2Fweb\%2Fsala-de-

imprensa\%2Fnoticias\%2Fvisualizar\%3Bjsessionid\%3D0AE9F4202795E669A807D2F3690AC4 7D\%3Fp_p_id\%3D101_INSTANCE_Mooje1VU08hX\%26p_p_lifecycle\%3D0\%26p_p_state\% 3Dnormal\%26p_p_mode\%3Dview\%26p_p_col_id\%3D_118_INSTANCE_6JBfezjkOU7u_col umn-2\%26p_p_col_count\%3D1>. Acesso em: 16 set. 2017.

SCHNEIDER, Jakob Robert. A prática das constelações familiares. 1. ed. Patos de Minas, MG: Atman, 2007.

STORCH, Sami. Publicado artigo sobre as primeiras experiências com constelações no judiciário. Direito Sistêmico, 23 de agosto de 2016. Disponível em: $<$ https://direitosistemico.wordpress.com/2016/08/23/publicado-artigo-sobre-as-primeirasexperiencias-com-constelacoes-no-judiciario/>. Acesso em: 13 set. 2017.

O direito sistêmico. Disponível em: <https://direitosistemico.wordpress.com/>. Acesso em: 12 set. 2017.

O que são as constelações sistêmicas, 30 de novembro de 2010. Notícia. Disponível em: <https://direitosistemico.wordpress.com/2010/11/30/o-que-sao-as-constelacoes-sistemica/>. Acesso em: 12 set. 2017.

Por que aprender direito sistêmico, 10 de abril de 2017. Disponível em: $\overline{\langle\text { https://direitosistemico.wordpress.com/2017/04/10/por-que-aprender-direito-sistemico/>. }}$ Acesso em: 12 set. 2017. 